\title{
Effect of excavation induced fractures on radionuclide migration through the Boom Clay (Belgium)
}

\author{
Marijke Huysmans ${ }^{a, *}$, Arne Berckmans ${ }^{b}$, Alain Dassargues ${ }^{a, c}$ \\ a Applied Geology and Mineralogy, Department of Geology-Geography, Katholieke Universiteit Leuven, \\ Celestijnenlaan 200 E, 3001 Heverlee, Belgium \\ ${ }^{\mathrm{b}}$ ONDRAF/NIRAS, Belgian Agency for Radioactive Waste and Enriched Fissile materials, Kunstlaan 14, 1210 Brussel, Belgium \\ ${ }^{\mathrm{c}}$ Hydrogeology, Department of Georesources, Geotechnologies and Building Materials, Université de Liège, Bât. B52, 4000 Liège, Belgium
}

Received 30 June 2005; received in revised form 31 May 2006; accepted 3 June 2006

Available online 12 July 2006

\begin{abstract}
In Belgium, the Boom Clay is being evaluated as a potential host formation for the disposal of high-level nuclear waste. In order to investigate this option, an underground research facility composed of two access shafts and $200 \mathrm{~m}$ of galleries was excavated. Excavation induced fractures were observed in a zone of approximately $1 \mathrm{~m}$ around the galleries. In this study, the potential effect of these fractures on radionuclide migration in the Boom Clay is investigated. Therefore, a hydrogeological model of the clay is built with a radionuclide source in the middle of the clay layer surrounded by different fracture configurations. Two types of fracture configurations are inserted in the model. The first type of fracture properties is drawn stochastically from the probability distributions of the properties of the fractures observed around previously excavated galleries. These fracture patterns are considered to be realistic although in this study it is conservatively assumed that no self-sealing occurs. The model is run for a large number of stochastically drawn fracture configurations and the results are compared to a model without fractures. These calculations show that the radionuclide fluxes through the clay are not significantly influenced by these fractures. For the second type of fracture configurations, the fracture properties are varied over a much larger range. Hypothetical fractures with much higher values of fracture extent, aperture, dip and frequency than observed are modeled. With these hypothetical fracture configurations, the critical values of the fracture parameters are determined that must be exceeded to have a significant effect on the radionuclide fluxes through the clay. These calculations show that the extent of the fractured zone has the largest effect on radionuclide migration. The other fracture parameters (aperture, spacing and dip) have a limited effect on the radionuclide fluxes. To obtain a total radionuclide flux through the lower clay boundary that is respectively $10 \%, 50 \%$ and $100 \%$ larger than without a fractured zone, the extent of the hypothetical fractured zone should be respectively $27.97 \mathrm{~m}, 43.86 \mathrm{~m}$ and $46.92 \mathrm{~m}$. Such fractures are not expected to be generated by mechanical excavation in the Boom Clay. The obtained critical extent values of the hypothetical fractures are a factor 30 to 40 higher than the measured values of the extent of the excavation disturbed zone. These calculations thus indicate that it is very unlikely that the extent of the fractured zone around the galleries will be large enough to have a significant effect on the radionuclide fluxes through the Boom Clay. This conclusion is further supported by the conservative assumption that no self-sealing occurs. These calculations can function as a preliminary robustness test in ongoing safety analysis studies.
\end{abstract}

(C) 2006 Elsevier B.V. All rights reserved.

Keywords: Waste disposal; Safety; Fractures; Radionuclides; Transport; Ground water models

\footnotetext{
* Corresponding author.

E-mail address: marijke.huysmans@geo.kuleuven.be (M. Huysmans).
} 


\section{Introduction}

The safe disposal of nuclear waste is an important environmental challenge. Several countries are investigating deep geological disposal as a long-term solution for high-level waste. In Belgium, France, Germany, Japan, Spain and Switzerland, clay layers are being considered as potential host formations (Landais, 2004). In Belgium, the Boom Clay is being evaluated as a potential host formation for the disposal of high-level nuclear waste (Fig. 1). This is a plastic clay of tertiary (Rupelian) age. In order to investigate this option, an underground research facility composed of two access shafts and $200 \mathrm{~m}$ of galleries was excavated in the Boom Clay at a depth of $223 \mathrm{~m}$ (HADESURF). Approximately $70 \mathrm{~m}$ of this gallery was excavated using an industrial technique and with minimal radial convergence.

Around the industrially excavated gallery, excavation induced fractures are observed. Fracture analysis carried out during recent tunnel excavation in the Boom Clay (Dehandschutter et al., 2002; Dehandschutter, 2002; Mertens et al., 2004) revealed that the most dominant discontinuities are part of a twofold conjugated fault set (Fig. 2). They are approximately parallel planes with an average spacing of around $70 \mathrm{~cm}$, a strike approximately perpendicular to the tunnel axis and a dip between $30^{\circ}$ and $80^{\circ}$. Fracturation and self-sealing processes in Boom (and Opalinus) Clay were studied in depth in the EC SELFRAC project (Bastiaens et al., 2005). The research performed in the framework of the SELFRAC project shows that the excavation induced fractures around a 4.8-m diameter gallery in the Boom Clay are limited to a zone of $1 \mathrm{~m}$. Moreover self-sealing processes, which will further limit

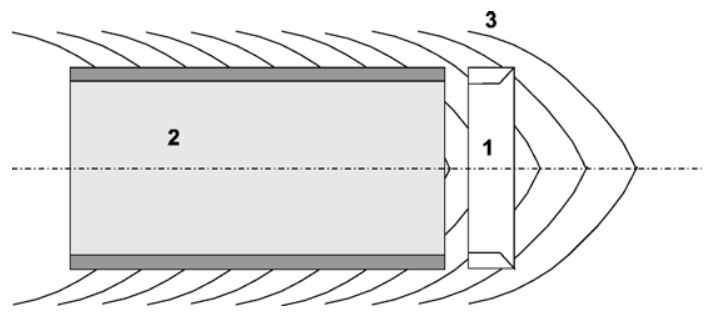

Fig. 2. Schematical representation of a vertical cross section through the Connecting Gallery showing the typical symmetrical form of the encountered shear planes (1. tunneling machine; 2. supported tunnel; 3. induced shear planes).

the influence of these fractures, have clearly been demonstrated in laboratory and in-situ experiments.

Outcrop investigations revealed the existence of a natural discontinuity network in the Boom Clay (Mertens et al., 2003) as in similar argillaceous media (Arnould et al., 2005). No evidence of the occurrence of natural discontinuities was however found at the depth of the underground research facility (Mertens et al., 2004). Therefore this paper only deals with excavation induced fractures in the Boom Clay.

In this study, the potential effect of excavation induced fractures on radionuclide migration in the Boom Clay is investigated. The aim of this paper is twofold. First, the effect of fractures similar to those observed around previously excavated galleries in the Boom Clay is examined. Secondly, hypothetical fractures are modeled to determine the critical values of the fracture parameters (fracture extent, aperture, dip and spacing) that must be exceeded to have a significant effect on the radionuclide fluxes through the clay.

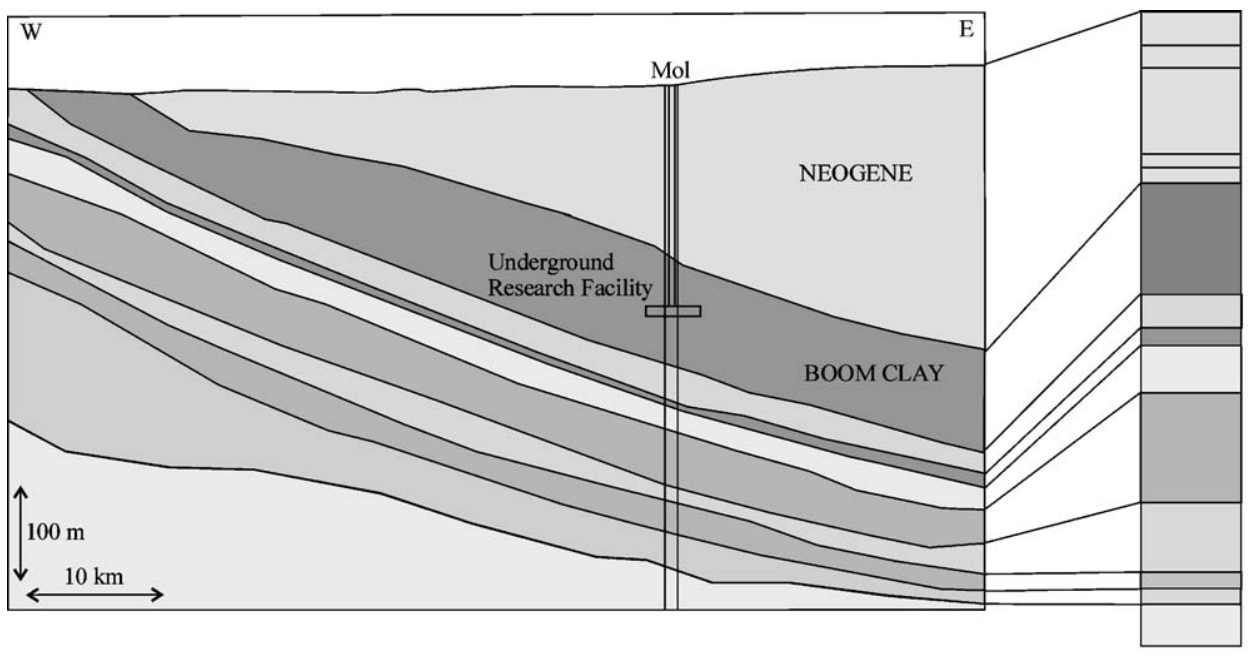

Sands of Mol Sands of Kasterlee Sands of Diest and Dessel Sands of Antwerp Sands of Voort Boom Clay Sands of Ruisbroek and Onderdale Asse Clay Sands of Lede and Brussel Ieper Clay and Sands Sands of Landen Landen Clay Marl of Gelinden Tuff of Maestricht

Fig. 1. Schematic view of Boom Clay and location of underground research facility (modified from Mallants et al., 2001). 


\section{Method}

The potential effect of excavation induced fractures on radionuclide migration through the Boom Clay is investigated in this study under the conservative assumption that no self-sealing occurs. A hydrogeological model of the clay is built with a radionuclide source located in the middle of the clay and surrounded by different realistic and hypothetical fracture configurations. The radionuclide flux through the upper and lower boundaries of the clay into the surrounding aquifers is calculated and compared to the flux calculated with a similar model without fractures.

Four different approaches are used to examine the effect of the fractures (Fig. 3). The first approach consists of inserting stochastic fracture configurations into the hydrogeological model. The properties of these fractures are drawn from probability distributions derived from measurements around previously excavated galleries. These fracture configurations are considered to be realistic although it is conservatively assumed that no self-sealing occurs. The other three approaches are designed to determine critical values of the fracture parameters. In these approaches, the
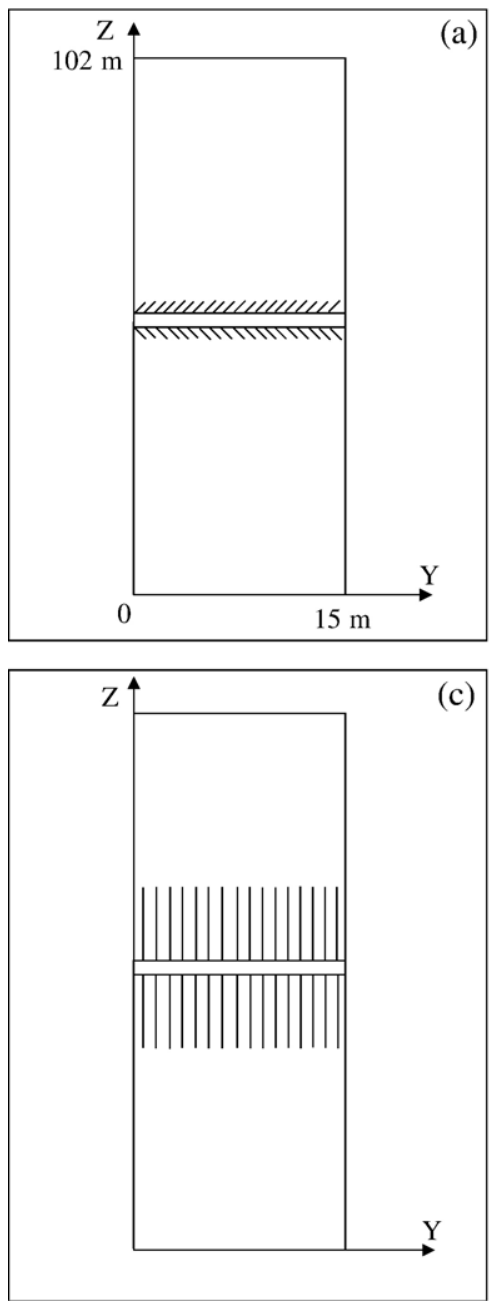

fracture parameters are therefore varied over a much larger range than observed. In the second approach, more specifically, the fractured zone is modeled as a hypothetical homogeneous zone with a larger hydraulic conductivity than the unfractured clay. The extent and hydraulic conductivity of this hypothetical permeable zone are varied over a large range. In this way, critical values for the extent and hydraulic conductivity of the permeable zone are determined. In the third approach, the fractured zone is modeled as a zone with hypothetical discrete vertical fractures. The fracture extent, aperture and frequency are varied over a large range to determine critical values for these parameters. In the fourth approach, the fractured zone is modeled as a zone with hypothetical discrete inclined fractures. The fracture orientation, extent, aperture and frequency are varied over a large range to determine critical values for these parameters.

\subsection{Hydrogeological model}

The hydrogeological model is a local 3D model of the Boom Clay. The model width in the $x$-direction is $20 \mathrm{~m}$, i.e. half the
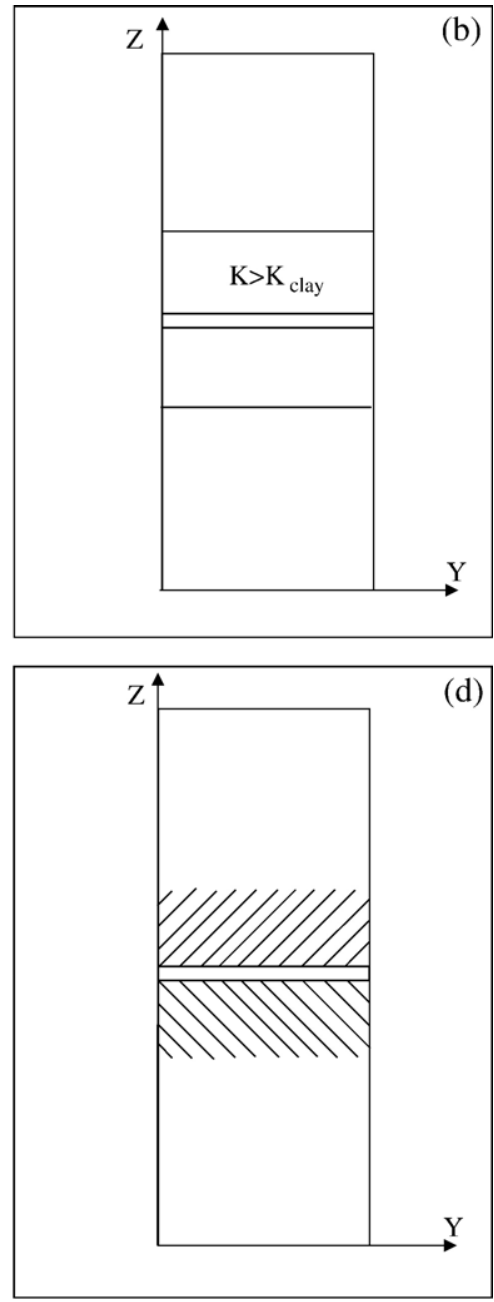

Fig. 3. Illustration of the four approaches: (a) stochastic fracture simulations, (b) permeable zone, (c) vertical fractures and (d) inclined fractures. 
assumed distance between the disposal galleries (Fig. 4). The model length in the $y$-direction for the first three approaches is $15 \mathrm{~m}$. This length was a compromise between including as many fractures as possible and keeping the computation time manageable. For the fourth approach, the model length in the $y$ direction is $100 \mathrm{~m}$ so that the model size is larger than the inclined fracture size in the $y$-direction. The model dimension in the $z$ direction is $102 \mathrm{~m}$, i.e. the total thickness of the Boom Clay in the nuclear zone of Mol-Dessel. The grid spacing is $1 \mathrm{~m}$ in the $x$ direction, approximately $0.7 \mathrm{~m}$ in the $y$-direction and $1 \mathrm{~m}$ in the $z$ direction. The average vertical hydraulic conductivity of the clay is $2.8 \mathrm{e}-12 \mathrm{~m} / \mathrm{s}$, the average horizontal conductivity of the clay is $7 \mathrm{e}-12 \mathrm{~m} / \mathrm{s}$ (Wemaere et al., 2002). The boundary conditions for groundwater flow and transport are shown in Fig. 5. The vertical boundary conditions for groundwater flow are zero flux boundary conditions since the hydraulic gradient is vertical. This means that although the model itself is fully three-dimensional, groundwater flow is one-dimensional vertical. The horizontal boundary conditions for groundwater flow are Dirichlet conditions. The specified head at the upper boundary is $2 \mathrm{~m}$ higher than the specified head at the lower boundary since the downward vertical hydraulic gradient is approximately 0.02 in the $100 \mathrm{~m}$ thick Boom Clay (Wemaere and Marivoet, 1995). This hydraulic gradient can of course change during the long time periods that are considered, but in this study it is assumed that the gradient remains constant. It is also assumed that the disposal gallery is completely backfilled and resaturated. The boundary conditions for transport at the upper and lower boundaries are zero concentration boundary conditions (Mallants et al., 1999) since the hydraulic conductivity contrast between the clay and the aquifer is so large that solutes reaching the boundaries are assumed to be flushed away by advection in the aquifer.

The transport model is calculated for 3 radionuclides: ${ }^{129} \mathrm{I}$, ${ }^{79} \mathrm{Se}$ and ${ }^{99} \mathrm{Tc}$. Previous calculations revealed that they were the most important in terms of dose rates from a potential high-level waste repository for vitrified waste (Mallants et al., 1999). The properties of these radionuclides are given in Table 1 . The transport processes that are taken into account in the model are advection, dispersion, molecular diffusion, linear and reversible sorption and radioactive decay.

The diameter of the disposal galleries is assumed to be $2 \mathrm{~m}$. The source term models for the 3 radionuclides are as described by Mallants et al., 1999. The radionuclides are contained in borosilicate glass and as the glass corrodes, the radionuclides become available for dissolution into the groundwater. A constant glass dissolution rate of $3 \mu \mathrm{m}$ per year was assumed. Since the initial radius of the cylindrical glass matrix would be $0.215 \mathrm{~m}$, the glass matrix would be completely dissolved after approximately 70,000 years. The source term model is therefore a constant flux over a period of 70,000 years equal to the total radionuclide inventory divided by 70,000 years. If, however, this source term model results in calculated concentrations higher than the solubility limit, the source term model is replaced by a constant concentration model. A constant concentration equal to the solubility limit is then prescribed until exhaustion of the source.

This local 3D hydrogeological model is run with FRAC3DVS, a simulator for three-dimensional groundwater flow and solute transport in porous, discretely-fractured porous or dual-porosity formations (Therrien and Sudicky, 1996; Therrien et al., 2003). The fractures are modeled as discrete planes with a saturated hydraulic conductivity (Bear, 1972):

$K_{f}=\frac{\rho g(2 \mathrm{~b})^{2}}{12 \mu}$

where $\rho$ is the fluid density $\left(\mathrm{kg} / \mathrm{m}^{3}\right), g$ is the acceleration due to gravity $\left(\mathrm{m} / \mathrm{s}^{2}\right), 2 \mathrm{~b}$ is the fracture aperture $(\mathrm{m})$ and $\mu$ is the fluid viscosity $(\mathrm{kg} /(\mathrm{ms}))$. For a fracture aperture of $50 \mu \mathrm{m}, K_{\mathrm{f}}$ is $6.25 \times 10^{-3} \mathrm{~m} / \mathrm{s}$. This means that the fractures have hydraulic conductivity values that are approximately one billion times larger than the hydraulic conductivity of unfractured Boom clay. Some authors have shown that Eq. (1) is not always valid, e.g., in roughly-walled fractures or in fractures deforming under changing stress conditions (e.g., Witherspoon et al., 1980).

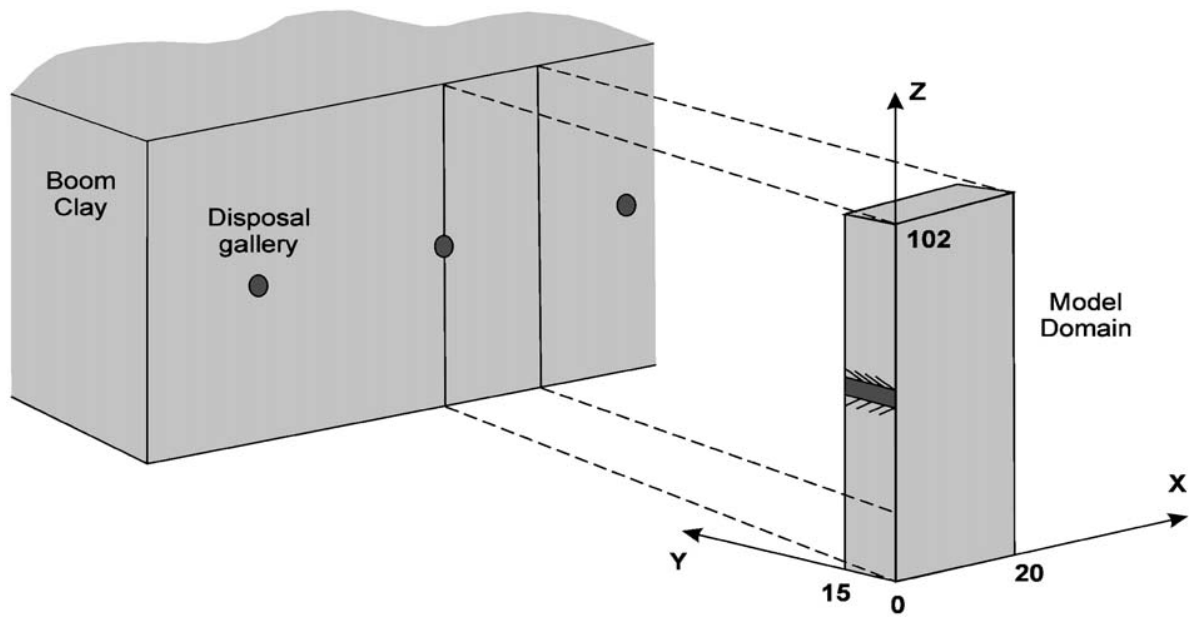

Fig. 4. Model domain of the 3D local hydrogeological model (Huysmans and Dassargues, 2005b). 

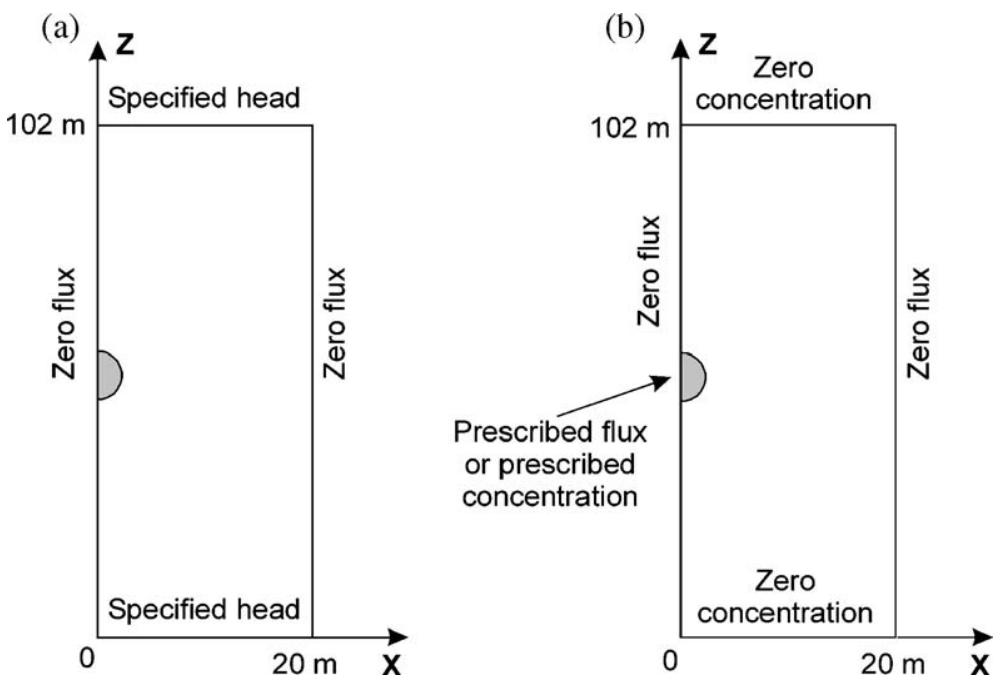

Fig. 5. Boundary conditions for (a) flow and (b) transport of the 3D local hydrogeological model (Huysmans and Dassargues, 2005b).

Several authors have shown that this equation overestimates the flow rate through fractures (e.g., Brown et al., 1995; Mourzenko et al., 1995; Yeo et al., 1998). This law is therefore a conservative law. This expression is however still the most widely used expression for fracture permeability and alternative expressions often require statistical data on the spatial variability of the fracture aperture which are usually not available.

\subsection{Stochastic fracture simulations based on observed fractures}

For the first approach, the properties (extent, aperture, spacing, dip and strike) of the fractures are drawn stochastically from the probability distributions of the properties of the fractures observed around the previously excavated galleries, assuming that the fractures around the future disposal galleries in the Boom Clay will probably have similar properties.

The extent of the fractures was simulated as a random number between $1 \mathrm{~m}$ and $3 \mathrm{~m}$. Fracture examination revealed that the Boom Clay seemed to be damaged up to approximately $2 \mathrm{~m}$ from the excavations (Mertens et al., 2004). Later research performed in the framework of the SELFRAC project shows that the excavation induced fractures around a 4.8-m diameter gallery in the Boom Clay are limited to a zone of $1 \mathrm{~m}$ (Bastiaens et al., 2005). Therefore, the average extent of the simulated fractures was set to a conservative value of $2 \mathrm{~m}$. To account for uncertainty in clay properties, tunnel design or excavation techniques, some variation of the extent of the fractured zone was allowed. The extent of the fractures was therefore drawn from a uniform distribution between $1 \mathrm{~m}$ and $3 \mathrm{~m}$.

Fracture apertures in the Boom Clay were examined using microtomography and scanning electron microscopy (Dehandschutter et al., 2004). Values of tens of micrometers were measured. The aperture can be as large as $1 \mathrm{~mm}$ at the tunnel walls and decreases rapidly in the clay as the distance to the excavation increases (Dehandschutter B., personal communication). There- fore, fracture aperture was simulated as a random number between $0 \mu \mathrm{m}$ and $50 \mu \mathrm{m}$.

Fracturing is very intense over most part of the excavation zone. The distance between subsequent fractures is generally less than $1 \mathrm{~m}$. The average spacing is about $70 \mathrm{~cm}$ (Mertens et al., 2004). The fracture spacing was drawn from a distribution reflecting these observations, i.e. a normal distribution with a mean of $0.70 \mathrm{~m}$ and a standard deviation of $0.12 \mathrm{~m}$.

Fracture dip angle varies between $30^{\circ}$ and $80^{\circ}$ (Dehandschutter et al., 2002). This variation is partially due to the curved nature of the fractures. 82 fracture dip measurements of shear faults were carried out (Dehandschutter, 2002). The average fracture dip was $53^{\circ}$ and the standard deviation was $11^{\circ}$. The fracture dip was therefore drawn from a normal distribution with a mean of $53^{\circ}$ and a standard deviation of $11^{\circ}$.

Examination of the strike of discontinuities surrounding boreholes and larger excavations in the Boom Clay revealed that the strike of most discontinuities was perpendicular to the borehole or gallery axis (Dehandschutter, 2002). The orientation of the fractures was fairly constant and all fractures were therefore assumed to have a strike perpendicular to the gallery axis.

For this study, a total of 10 realizations of fracture geometry and properties are simulated by independent sampling from the

Table 1

Properties of selected radionuclides (values are taken from Mallants et al., 1999)

\begin{tabular}{|c|c|c|c|}
\hline & ${ }^{79} \mathrm{Se}$ & ${ }^{129} \mathrm{I}$ & ${ }^{99} \mathrm{Tc}$ \\
\hline Half-life (year) & $6.50 \times 10^{4}$ & $1.57 \times 10^{7}$ & $2.13 \times 10^{5}$ \\
\hline Decay constant (year $\left.{ }^{-1}\right)$ & $1.07 \times 10^{-5}$ & $4.41 \times 10^{-8}$ & $3.25 \times 10^{-6}$ \\
\hline Solubility limit (mol/l) & $5.5 \times 10^{-8}$ & - & $3 \times 10^{-8}$ \\
\hline Diffusion coefficient $\left(\mathrm{m}^{2} / \mathrm{s}\right)$ & $2 \times 10^{-10}$ & $2 \times 10^{-10}$ & $2 \times 10^{-10}$ \\
\hline $\begin{array}{l}\text { Diffusion accessible porosity } \\
\qquad(-)\end{array}$ & 0.13 & 0.12 & 0.30 \\
\hline Retardation factor $(-)$ & 1 & 1 & 1 \\
\hline
\end{tabular}


proposed marginal distributions of fracture extent, aperture, spacing, dip and strike. The model results are compared to the results of a model without fractures.

\subsection{Simulation of a hypothetical permeable zone}

In the second approach, the fractured zone is modeled as a homogeneous cylindrical zone around the gallery with a higher hydraulic conductivity than the unfractured clay. The thickness of this hypothetical permeable zone is varied between 0 and $49 \mathrm{~m}$. The hydraulic conductivity value of this hypothetical permeable zone is varied between $2.8 \mathrm{e}-12$ and $2.8 \mathrm{e}-6 \mathrm{~m} / \mathrm{s}$. The radionuclide fluxes through the clay are calculated for 18 combinations of thickness and hydraulic conductivity of the permeable zone.

Instead of determining critical values of permeable zone extent and hydraulic conductivity, the critical value of the total equivalent vertical hydraulic conductivity of the medium is determined. This is done because the respective critical values of the extent and hydraulic conductivity depend on the value of the other parameter. Equivalent vertical hydraulic conductivity is a single parameter which depends both on the extent and the hydraulic conductivity of the permeable zone. The equivalent vertical hydraulic conductivity for the total thickness of the Boom Clay is defined as the weighted harmonic mean of the hydraulic conductivity values of the permeable zone and the undisturbed Boom clay:

$K_{\text {eq }}=\frac{D}{\frac{d}{K_{\text {perm }}}+\frac{D-d}{K_{\text {clay }}}}$

where $K_{\text {eq }}(\mathrm{m} / \mathrm{s})$ is the equivalent vertical hydraulic conductivity of the medium, $D(\mathrm{~m})$ is half of the total thickness of the medium, $d(\mathrm{~m})$ is the thickness of the permeable zone, $K_{\text {perm }}(\mathrm{m} / \mathrm{s})$ is the vertical hydraulic conductivity of the permeable zone and $K_{\text {clay }}$ $(\mathrm{m} / \mathrm{s})$ is the hydraulic conductivity of the undisturbed clay.

The relation between the computed radionuclides fluxes and equivalent vertical hydraulic conductivity is calculated. Critical values of equivalent vertical hydraulic conductivity are determined and translated to critical values of permeable zone extent and hydraulic conductivity.

\subsection{Simulation of hypothetical vertical fractures}

In the third approach, a hypothetical fractured zone is modeled as a cylindrical zone around the gallery with discrete vertical fractures. Radionuclide fluxes were calculated for 11 different combinations of fracture spacing, aperture and extent. Fracture spacing was varied between 0 and $0.7 \mathrm{~m}$. Fracture aperture was varied between 0 and $1 \mathrm{~mm}$. The fractured zone extent was varied between 0 and $49 \mathrm{~m}$.

Critical values for equivalent vertical hydraulic conductivity were determined. The same formula for equivalent vertical hydraulic conductivity holds, but $K_{\text {perm }}$ is now dependent on the spacing and aperture of the vertical fractures.

$K_{\text {perm }}=\frac{K_{\mathrm{m}} S+K_{\mathrm{f}}(2 \mathrm{~b})}{S+2 b}$
$K_{f}=\frac{\rho g(2 b)^{2}}{12 \mu}$

where $K_{\text {perm }}(\mathrm{m} / \mathrm{s})$ is the vertical hydraulic conductivity of the fractured zone, $K_{\mathrm{m}}(\mathrm{m} / \mathrm{s})$ is the hydraulic conductivity of the matrix material between the fractures in the fractured zone, $S(\mathrm{~m})$ is the fracture spacing, $2 \mathrm{~b}(\mathrm{~m})$ is the fracture aperture, $K_{\mathrm{f}}$ is the fracture permeability, $\rho$ is the fluid density $\left(\mathrm{kg} / \mathrm{m}^{3}\right), g$ is the acceleration due to gravity $\left(\mathrm{m} / \mathrm{s}^{2}\right)$ and $\mu$ is the fluid viscosity $(\mathrm{kg} /$ $(\mathrm{ms})$ ).

The relation between the computed radionuclides fluxes and equivalent vertical hydraulic conductivity is calculated. Critical values of equivalent vertical hydraulic conductivity are determined and translated to critical values of fracture extent, spacing and aperture.

\subsection{Simulation of hypothetical inclined fractures}

In the fourth approach, a hypothetical fractured zone is modeled as a cylindrical zone around the gallery with discrete inclined fractures. Radionuclide fluxes were calculated for 11 different combinations of fracture dip, spacing, aperture and extent. Fracture dip was varied between $25^{\circ}$ and $90^{\circ}$. Fracture spacing was varied between 0 and $0.7 \mathrm{~m}$. Fracture aperture was varied between 0 and $1 \mathrm{~mm}$. The fractured zone extent was varied between 0 and $49 \mathrm{~m}$.

Critical values for equivalent vertical hydraulic conductivity were determined. The same formula for equivalent vertical hydraulic conductivity holds, but $K_{\text {perm }}$ is now dependent on the dip, spacing and aperture of the vertical fractures.

$K_{\text {perm }}=K_{/ /} \cos ^{2} \theta+K_{\perp} \sin ^{2} \theta$

$K_{/ /}=\frac{K_{m} S+K_{\mathrm{f}}(2 \mathrm{~b})}{S+2 \mathrm{~b}}$

$K_{\perp}=\frac{S+2 \mathrm{~b}}{\frac{S}{K_{\mathrm{m}}}+\frac{2 \mathrm{~b}}{K_{\mathrm{f}}}}$

$K_{\mathrm{f}}=\frac{\rho g(2 \mathrm{~b})^{2}}{12 \mu}$

where $\theta$ is the fracture dip $\left({ }^{\circ}\right), K_{\text {perm }}(\mathrm{m} / \mathrm{s})$ is the vertical hydraulic conductivity of the fractured zone, $K_{\mathrm{m}}(\mathrm{m} / \mathrm{s})$ is the hydraulic conductivity of the matrix material between the fractures in the fractured zone, $S(\mathrm{~m})$ is the fracture spacing, $2 \mathrm{~b}$ $(\mathrm{m})$ is the fracture aperture, $K_{\mathrm{f}}$ is the fracture permeability, $\rho$ is the fluid density $\left(\mathrm{kg} / \mathrm{m}^{3}\right), g$ is the acceleration due to gravity $\left(\mathrm{m} / \mathrm{s}^{2}\right)$ and $\mu$ is the fluid viscosity $(\mathrm{kg} /(\mathrm{ms}))$.

The relation between the computed radionuclides fluxes and equivalent vertical hydraulic conductivity is calculated. Critical values of equivalent vertical hydraulic conductivity are 

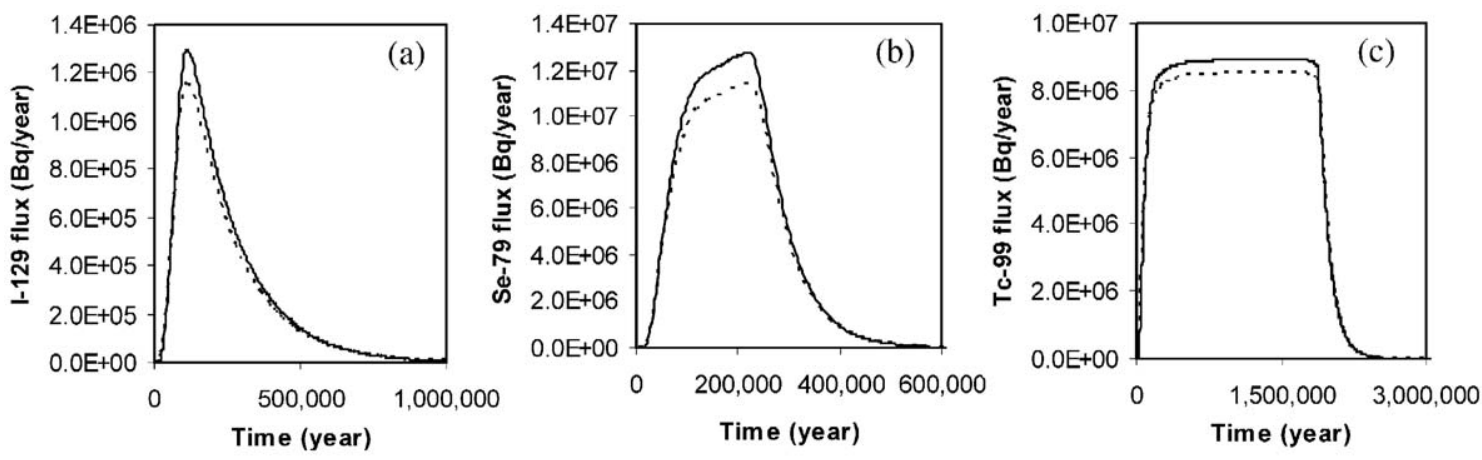

\section{Legend}

- Flux through lower clay boundary

- - - - - - Flux through upper clay boundary

Fig. 6. Computed radionuclide fluxes of (a) ${ }^{129} \mathrm{I},(\mathrm{b}){ }^{79} \mathrm{Se}$ and (c) ${ }^{99} \mathrm{Tc}$ through the lower and the upper clay boundary versus time for one realization.

determined and translated to critical values of fracture extent, spacing, dip and aperture.

\section{Results and discussion}

\subsection{Stochastic fracture simulations based on observed fractures}

Fig. 6 shows the computed radionuclide fluxes versus time for one stochastic fracture simulation. The fluxes through the lower clay boundary are slightly larger than the fluxes through the upper clay boundary due to the small downward groundwater flow. For ${ }^{129} \mathrm{I}$, the fluxes through the clay-aquifer interfaces increase until they reach a maximum after approximately 120,000 years and decrease gradually afterwards. The ${ }^{79} \mathrm{Se}$ fluxes through the clayaquifer interfaces increase until they reach a maximum after approximately 200,000 years and decrease slowly

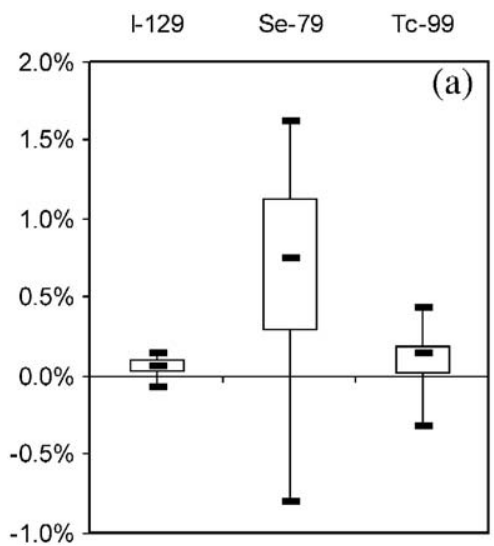

afterwards due to exhaustion of the source. The ${ }^{99} \mathrm{Tc}$ fluxes through the clay-aquifer interfaces increase relatively fast the first 200,000 years. From 200,000 until 1,750,000 years, the fluxes increase more gradually. The fluxes decrease afterwards due to exhaustion of the source.

Total radionuclide activities $(\mathrm{Bq})$ are calculated by integrating the computed radionuclide fluxes through the clay boundaries over time. The total radionuclide activities calculated for each of the 10 fracture simulations are compared with the total radionuclide activities of a hydrogeological model without fractures. In Fig. 7, a comparison is made between the radionuclide masses calculated with hydrogeological models with and without fractures. The figures show boxplots of the difference in percentage of the computed total radionuclide mass between the 10 models with stochastic fracture simulations and a homogeneous model without fractures. The

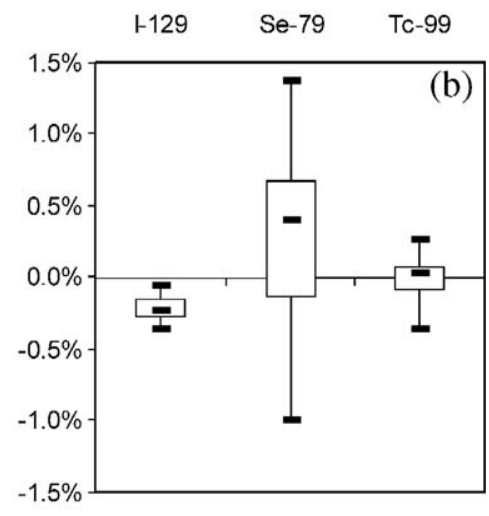

Fig. 7. Boxplots of difference in percentage of total computed radionuclide activity between models with and without fractures (a) through the lower clay-aquifer interface and (b) through the upper clay-aquifer interface. 
difference is the largest for ${ }^{79} \mathrm{Se}$. Compared to the homogeneous model, the radionuclide mass flowing through the lower clay-aquifer is between $0.8 \%$ smaller and $1.6 \%$ larger in the model with fractures. The radionuclide mass flowing through the upper clay-aquifer is between $1 \%$ smaller and $1.4 \%$ larger.
The computed total radionuclide activities of the models with stochastic fracture simulations are at most $1.6 \%$ larger than the radionuclide activities of a homogeneous model without fractures. This indicates that fractures with properties similar to the fractures observed around previously excavated galleries in the
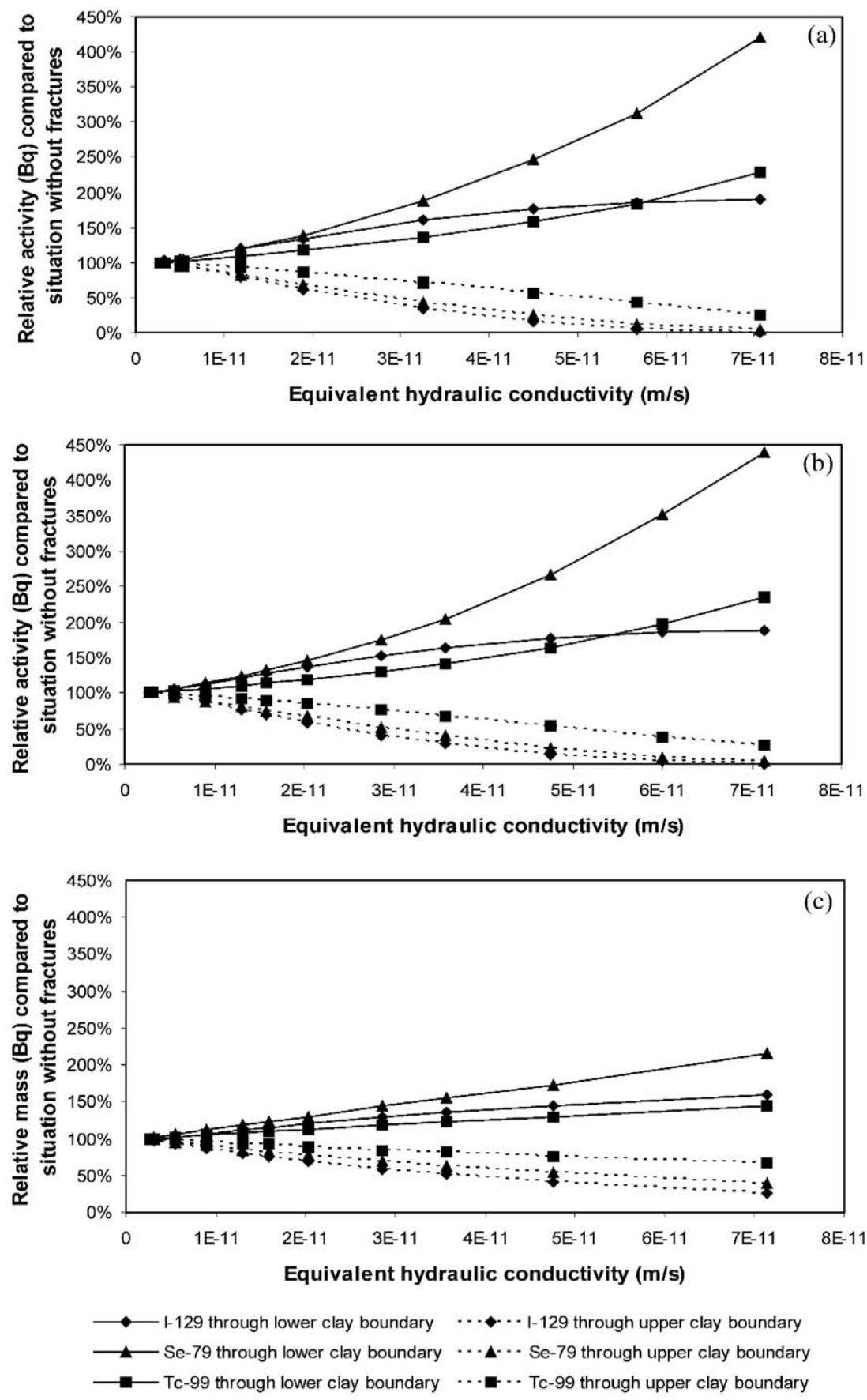

Fig. 8. Computed total relative radionuclide activities versus equivalent hydraulic conductivity with (a) a homogeneous permeable zone, (b) a zone with vertical fractures and (c) a zone with inclined fractures with fracture dip $=55^{\circ}$ around the gallery. 
Table 2

Critical values of equivalent vertical hydraulic conductivity of permeable zone models to obtain computed total radionuclide activities that are $10 \%, 50 \%$ and $100 \%$ higher than calculated with homogeneous model

\begin{tabular}{llll}
\hline & ${ }^{129} \mathrm{I}$ & ${ }^{79} \mathrm{Se}$ & ${ }^{99} \mathrm{Tc}$ \\
\hline $10 \%$ & $8 \mathrm{e}-12 \mathrm{~m} / \mathrm{s}$ & $7.5 \mathrm{e}-12 \mathrm{~m} / \mathrm{s}$ & $6.2 \mathrm{e}-12 \mathrm{~m} / \mathrm{s}$ \\
$50 \%$ & $2 \mathrm{e}-11 \mathrm{~m} / \mathrm{s}$ & $2.25 \mathrm{e}-11 \mathrm{~m} / \mathrm{s}$ & $4 \mathrm{e}-11 \mathrm{~m} / \mathrm{s}$ \\
$100 \%$ & $8 \mathrm{e}-11 \mathrm{~m} / \mathrm{s}$ & $3.5 \mathrm{e}-11 \mathrm{~m} / \mathrm{s}$ & $6.2 \mathrm{e}-11 \mathrm{~m} / \mathrm{s}$ \\
\hline
\end{tabular}

Boom Clay have no significant effect on the radionuclide fluxes through the clay. The limited extent of the fractured zone guarantees that the thickness of unfractured Boom Clay is large enough to limit the effect of the fractures.

The radionuclide ${ }^{79}$ Se shows a larger variation than the other radionuclides. This can be explained by the relatively low diffusion accessible porosity and high decay constant of ${ }^{79} \mathrm{Se}$. As the porosity is lower, transport by diffusion is less important compared to transport by advection, as indicated by the Péclet number for low permeability environments (Huysmans and Dassargues, 2005a)

$P e=\frac{V_{\mathrm{D}} x}{n D_{\mathrm{e}}}$

where $V_{\mathrm{D}}(\mathrm{m} / \mathrm{s})$ is the Darcy velocity, $x(\mathrm{~m})$ is a distance, $n$ (-)is the diffusion accessible porosity and $D_{\mathrm{e}}\left(\mathrm{m}^{2} / \mathrm{s}\right)$ is the effective diffusion coefficient. If porosity decreases, the Péclet number increases. This means that transport by advection becomes more important. If transport by advection is more important, the effect of a change in hydraulic conductivity is larger. Since changes in fracture parameters can be seen as changes in equivalent hydraulic conductivity, radionuclides with a lower diffusion accessible porosity are more sensitive to changes in fracture parameters. The effect of a high decay constant can be explained as follows. For decaying solutes, fractures not only decrease the travel time, but they also decrease the amount of solute that has been decayed before arrival. The larger the decay constant, the larger the effect of fractures on the solutes fluxes.

\subsection{Simulation of a hypothetical permeable zone}

The computed total radionuclide activities through the upper and lower clay boundaries (relative to the total radionuclide activities calculated with a model without fractures) versus equivalent hydraulic conductivity of the medium are shown in Fig. 8a. As equivalent hydraulic conductivity increases, the total radionuclide activity through the lower clay boundary increases, while the total radionuclide activity through the upper clay boundary decreases. The total radionuclide activity through the lower clay boundary increases the most for ${ }^{79} \mathrm{Se}$, which is caused by the relatively low diffusion accessible porosity and high decay constant of ${ }^{79} \mathrm{Se}$, as explained in the previous section.

Critical equivalent hydraulic conductivities to obtain a certain flux increase are derived from the figure (Table 2). The critical equivalent hydraulic conductivity values for the total thickness of the Boom Clay can be translated into critical values of hypothetical permeable zone extent and permeable zone hydraulic conductivity. For different values of the hydraulic conductivity of the permeable zone, the critical extent of a hypothetical permeable zone is determined by rearranging the expression of equivalent hydraulic conductivity (2):

$d=\frac{D\left(\frac{1}{K_{\text {clay }}}-\frac{1}{K_{\text {eq }}}\right)}{\frac{1}{K_{\text {clay }}}-\frac{1}{K_{\text {perm }}}}$

The extent of the hypothetical permeable zone to obtain a total radionuclide activity $10 \%, 50 \%$ and $100 \%$ larger than without a permeable zone is calculated for several permeable zone hydraulic conductivity values (Table 3). The critical extent of the permeable zone to obtain a certain total radionuclide activity is rather insensitive to the hydraulic conductivity of the permeable zone. The main parameter that determines the equivalent hydraulic conductivity, and thus the calculated radionuclide fluxes, is the extent of the permeable zone. To obtain a total radionuclide activity 10\%, 50\% and $100 \%$ larger than without a permeable zone, a minimum extent of a hypothetical permeable zone of respectively $27.97 \mathrm{~m}, 43.86 \mathrm{~m}$ and $46.92 \mathrm{~m}$ is needed. These values are 30 to 40 times larger than the observed values of the extent of the excavation disturbed zone

Table 3

Critical values of permeable zone extent to obtain computed total radionuclide activities that are $10 \%, 50 \%$ and $100 \%$ higher than calculated with homogeneous model

\begin{tabular}{llllll}
\hline & & $K_{\text {perm }}=\infty$ & $\begin{array}{l}K_{\text {perm }}=1.3 \mathrm{e} \\
-7 \mathrm{~m} / \mathrm{s}\end{array}$ & $\begin{array}{l}K_{\text {perm }}=1 \mathrm{e} \\
-9 \mathrm{~m} / \mathrm{s}\end{array}$ & $\begin{array}{l}K_{\text {perm }}=1 \mathrm{e} \\
-10 \mathrm{~m} / \mathrm{s}\end{array}$ \\
\hline $10 \%$ & ${ }^{129} \mathrm{I}$ & $33.15 \mathrm{~m}$ & $33.15 \mathrm{~m}$ & $33.24 \mathrm{~m}$ & $34.10 \mathrm{~m}$ \\
& ${ }^{79} \mathrm{Se}$ & $31.96 \mathrm{~m}$ & $31.96 \mathrm{~m}$ & $32.05 \mathrm{~m}$ & $32.88 \mathrm{~m}$ \\
& ${ }^{99} \mathrm{Tc}$ & $27.97 \mathrm{~m}$ & $27.97 \mathrm{~m}$ & $28.05 \mathrm{~m}$ & $28.77 \mathrm{~m}$ \\
$50 \%$ & ${ }^{129} \mathrm{I}$ & $43.86 \mathrm{~m}$ & $43.86 \mathrm{~m}$ & $43.98 \mathrm{~m}$ & $45.12 \mathrm{~m}$ \\
& ${ }^{79} \mathrm{Se}$ & $44.65 \mathrm{~m}$ & $44.65 \mathrm{~m}$ & $44.78 \mathrm{~m}$ & $45.94 \mathrm{~m}$ \\
& ${ }^{99} \mathrm{Tc}$ & $47.43 \mathrm{~m}$ & $47.43 \mathrm{~m}$ & $47.56 \mathrm{~m}$ & $48.80 \mathrm{~m}$ \\
$100 \%$ & ${ }^{129} \mathrm{I}$ & $49.22 \mathrm{~m}$ & $49.22 \mathrm{~m}$ & $49.35 \mathrm{~m}$ & $50.63 \mathrm{~m}$ \\
& ${ }^{79} \mathrm{Se}$ & $46.92 \mathrm{~m}$ & $46.92 \mathrm{~m}$ & $47.05 \mathrm{~m}$ & $48.27 \mathrm{~m}$ \\
& ${ }^{99} \mathrm{Tc}$ & $48.70 \mathrm{~m}$ & $48.70 \mathrm{~m}$ & $48.83 \mathrm{~m}$ & $50.10 \mathrm{~m}$ \\
\hline
\end{tabular}


Table 4

Critical values of equivalent vertical hydraulic conductivity of models with inclined fractures to obtain computed total radionuclide activities that are $10 \%, 50 \%$ and $100 \%$ higher than calculated with homogeneous model

\begin{tabular}{llll}
\hline & ${ }^{129} \mathrm{I}$ & ${ }^{79} \mathrm{Se}$ & ${ }^{99} \mathrm{Tc}$ \\
\hline $10 \%$ & $1.3 \mathrm{e}-11 \mathrm{~m} / \mathrm{s}$ & $8 \mathrm{e}-12 \mathrm{~m} / \mathrm{s}$ & $1.8 \mathrm{e}-11 \mathrm{~m} / \mathrm{s}$ \\
$50 \%$ & $5.3 \mathrm{e}-11 \mathrm{~m} / \mathrm{s}$ & $3 \mathrm{e}-11 \mathrm{~m} / \mathrm{s}$ & $8 \mathrm{e}-11 \mathrm{~m} / \mathrm{s}$ \\
$100 \%$ & $1.3 \mathrm{e}-10 \mathrm{~m} / \mathrm{s}$ & $6.3 \mathrm{e}-11 \mathrm{~m} / \mathrm{s}$ & $1.6 \mathrm{e}-10 \mathrm{~m} / \mathrm{s}$ \\
\hline
\end{tabular}

around galleries in the Boom Clay. These calculations thus indicate that it is very unlikely that the extent of the permeable zone around the galleries will be large enough to have a significant effect on the radionuclide fluxes through the clay.

\subsection{Simulation of hypothetical vertical fractures}

The computed total radionuclide activities through the upper and lower clay boundaries versus equivalent hydraulic conductivity of the medium are shown in Fig. $8 \mathrm{~b}$. This figure is almost identical to Fig. 8a. This means that in the case of vertical fractures, the discrete fractures must not be modeled explicitly, but can be replaced by an equivalent homogeneous medium with the appropriate vertical hydraulic conductivity calculated with Eq. (3). The critical values of equivalent hydraulic conductivity calculated with the homogeneous permeable zone approach are also valid for the vertical fractures approach.

The critical equivalent hydraulic conductivity values can be translated into critical values of fracture extent, spacing and aperture. Sensitivity analysis shows however that equivalent hydraulic conductivity is rather insensitive to fracture spacing and aperture. The main parameter that determines the equivalent hydraulic conductivity, and thus the radionuclide fluxes, is the extent of the permeable zone. The critical values of the fractured zone extent are identical to the critical values of permeable zone extent calculated in the previous section. This again means that the fracture extent values should be much larger than realistic values of the extent of the fractured zone to have a significant effect on radionuclide migration.

\subsection{Simulation of hypothetical inclined fractures}

For inclined fractures, the computed total radionuclide activities are not only dependent on the equivalent hydraulic conductivity but also on the fracture dip. This is probably due to the limited size of the model domain in the $y$-direction compared to the size of the fractures in the $y$-direction, so that an equivalent medium approach is not appropriate. The computed total radionuclide activities through the upper and lower clay boundaries versus equivalent hydraulic conductivity of the medium are shown in Fig. 8c for hypothetical fractures with a fracture dip of $55^{\circ}$. The curves show the same trend as the curves for hypothetical vertical fractures: as equivalent hydraulic conductivity increases, the total radionuclide activity through the lower clay boundary increases, while the total radionuclide activity through the upper clay boundary decreases. The increase of the total radionuclide activity through the lower clay boundary is however not as large as for vertical fractures. The calculated radionuclide fluxes are smaller than the fluxes calculated by an equivalent homogeneous model with the appropriate vertical hydraulic conductivity.

Critical equivalent hydraulic conductivities to obtain a certain flux increase are derived from the figure (Table 4). The critical equivalent hydraulic conductivity values can be translated into critical values of fractured zone extent. The critical extent of the hypothetical fractured zone is determined by rearranging the expression of equivalent hydraulic conductivity. The extent of the hypothetical fractured zone to obtain a certain total calculated radionuclide activity is rather insensitive to the fracture aperture, dip and spacing. The main parameter that determines the equivalent hydraulic conductivity, and thus the radionuclide fluxes, is the extent of the fractured zone. The extent of the fractured zone to obtain a total radionuclide activity $10 \%, 50 \%$ and $100 \%$ larger than with a homogeneous model is shown in Table 5 for inclined fractures with a fracture dip of $55^{\circ}$. To obtain a total radionuclide activity $10 \%, 50 \%$ and $100 \%$ larger than without a permeable zone, a minimum extent of the permeable zone of respectively $33.15 \mathrm{~m}, 46.24 \mathrm{~m}$ and $48.73 \mathrm{~m}$ is needed. These critical fractured zone extent values are larger than for vertical fractures. It is clear that these values are again much larger than realistic values of the extent of the excavation disturbed zone around galleries in the Boom Clay.

Table 5

Critical values of fractured zone extent with inclined fractures (fracture dip of $55^{\circ}$ ) to obtain computed total radionuclide activities that are $10 \%, 50 \%$ and $100 \%$ higher than calculated with homogeneous model

\begin{tabular}{llll}
\hline & ${ }^{129} \mathrm{I}$ & ${ }^{79} \mathrm{Se}$ & ${ }^{99} \mathrm{Tc}$ \\
\hline $10 \%$ & $40.02 \mathrm{~m}$ & $33.15 \mathrm{~m}$ & $43.07 \mathrm{~m}$ \\
$50 \%$ & $48.31 \mathrm{~m}$ & $46.24 \mathrm{~m}$ & $49.22 \mathrm{~m}$ \\
$100 \%$ & $49.90 \mathrm{~m}$ & $48.73 \mathrm{~m}$ & $50.11 \mathrm{~m}$ \\
\hline
\end{tabular}




\section{Conclusions}

The main conclusions of this study are the following.

1. Fractures with properties similar to the fractures observed around previously excavated galleries in the Boom Clay have no significant effect on the radionuclide fluxes through the clay. The limited extent of the fractured zone guarantees that the thickness of unfractured Boom Clay is large enough to limit the effect of the fractures. This conclusion is strengthened by the conservative assumptions that (1) no self-sealing occurs, (2) the fracture extent in the model is between 1 and $3 \mathrm{~m}$ for a $2-\mathrm{m}$ gallery while the reported extent around a $4.8 \mathrm{~m}$ diameter gallery is only $1 \mathrm{~m}$ and (3) fracture permeability is calculated using the cubic law which tends to overestimate fracture permeability in materials such as the Boom Clay.

2. The effect of fractures on solute fluxes increases with decreasing diffusion accessible porosity and increasing decay constant. The radionuclide ${ }^{79} \mathrm{Se}$ shows a larger sensitivity of the radionuclide flux to fracture properties than ${ }^{129} \mathrm{I}$ and ${ }^{99} \mathrm{Tc}$.

3. From all fracture parameters, the extent of the fractured zone has the largest effect on radionuclide migration. The other fracture parameters aperture, spacing and dip have a limited effect on the radionuclide fluxes. This is a direct consequence of the fact that fracture permeability following Eq. (1) is extremely high compared to the permeability of intact rock. Since Eq. (1) tends to overestimate fracture permeability, the other fracture parameters may be more important if a more realistic law for fracture permeability is used.

4. For the radionuclides considered $\left({ }^{129} \mathrm{I},{ }^{79} \mathrm{Se}\right.$ and $\left.{ }^{99} \mathrm{Tc}\right)$, a minimum extent of a hypothetical permeable zone of respectively $27.97 \mathrm{~m}, 43.86 \mathrm{~m}$ and $46.92 \mathrm{~m}$ is needed to obtain a radionuclide activity $10 \%, 50 \%$ and $100 \%$ larger than without a permeable zone. These values are 30 to 40 times larger than the observed value of $1 \mathrm{~m}$ of the extent of the excavation disturbed zone around galleries in the Boom Clay. The critical values of the permeable zone extent may however be smaller for radionuclides with a smaller diffusion accessible porosity or a larger decay constant than the radionuclides considered in this study.

5. In the case of vertical fractures, the discrete fractures must not be modeled explicitly, but can be replaced by an equivalent homogeneous medium with the appropriate equivalent vertical hydraulic conductivity.

6. For inclined fractures, the model cannot be replaced by an equivalent homogeneous medium with the appropriate vertical hydraulic conductivity. The calculated radionuclide fluxes are smaller than the fluxes calculated by an equivalent homogeneous model with the appropriate vertical hydraulic conductivity. For inclined fractures with a dip of $55^{\circ}$, the critical values of the hypothetical fractured zone extent are even larger than for vertical fractures. These values are also much larger than realistic values of the extent of the excavation disturbed zone around galleries in the Boom Clay.

These calculations thus indicate that it is very unlikely that the extent of the fractured zone around the galleries will be large enough to have a significant effect on the radionuclide fluxes through the clay. Permanently open fractures of at least $30 \mathrm{~m}$ long would be required to increase the flux of the most critical radionuclides through the lower Boom Clay boundary with $10 \%$. The statement is further supported by the conservative assumption that no self-sealing occur. These calculations can function as a preliminary robustness test in ongoing safety analysis studies.

It must however be noted that in this research only fractures around horizontal galleries are included. The fractured zone around the vertical shaft connecting the galleries with the surface is not modeled. This fractured zone around the vertical shaft may possibly be a fast pathway for radionuclides to the surface and will be subject of further research.

\section{Acknowledgements}

The authors wish to acknowledge the Fund for Scientific Research — Flanders for providing a Research Assistant scholarship to the first author. We also thank René Therrien and Rob McLaren for providing FRAC3DVS and for their assistance. We also wish to thank ONDRAF/NIRAS (Belgium agency for radioactive waste and enriched fissile materials) and SCK-CEN (Belgian Nuclear Research Centre) for their input and assistance.

\section{References}

Arnould, M., Mazurek, M., Vandenberghe, N., 2005. Discontinuity networks in mudstones: an apparent contradiction for Boom Clay at Mol, Opalinus Clay at Mont Terri, Callovo-Oxfordian silty clay at Bure. International Meeting on Clays in Natural and Engineered Barriers for Radioactive Waste Confinement, Tours. ANDRA, Châtenay-Malabry Cedex, France, pp. 479-480.

Bastiaens, W., Bernier, F., Ling Li, X., 2005. SELFRAC: experiments and conclusions on fracturation and self-healing processes in clays. International Meeting on Clays in Natural and Engineered Barriers 
for Radioactive Waste Confinement, Tours. ANDRA, ChâtenayMalabry Cedex, France, pp. 135-136.

Bear, J., 1972. Dynamics of Fluids in Porous Media. American Elsevier, New York.

Brown, S.R., Stockman, H.W., Reeves, S.J., 1995. Applicability of the Reynolds equation for modeling fluid flow between rough surfaces. Geophysical Research Letters 22, 2537-2540.

Dehandschutter, B., 2002. Faulting and Fracturing during Connecting Gallery tunnelling at the URL at Mol (SCK-CEN)- ONDRAF/NIRAS unpublished internal report. ONDRAF/NIRAS, Brussel(Belgium).

Dehandschutter, B., Sintubin, M., Vandenberghe, N., Vandycke, S., Gaviglio, P., Wouters, L., 2002. Fracture analysis in the Boom Clay (URF, Mol, Belgium). Aardkundige Mededelingen 12, 245-248.

Dehandschutter, B., Vandycke, S., Sintubin, M., Vandenberghe, N., Gaviglio, P., Sizun, J.-P., Wouters, L., 2004 . Microfabric of fractured Boom Clay at depth: a case study of brittle-ductile transitional clay behaviour. Applied Clay Science 26 (1-4), 389-401.

Huysmans, M., Dassargues, A., 2005a. Review of the use of Péclet numbers to determine the relative importance of advection and diffusion in low permeability environments. Hydrogeology Journal 13 (5-6), 895-904.

Huysmans, M., Dassargues, A., 2005b. Stochastic analysis of the effect of heterogeneity and fractures on radionuclide transport in a low permeability clay layer. Environmental Geology 48 (7), 920-930.

Landais, P., 2004. Clays in natural and engineered barriers for radioactive waste confinement. Applied Clay Science 26 (1-4), 1.

Mallants, D., Sillen, X., Marivoet, J., 1999. Geological disposal of conditioned high-level and long lived radioactive waste: consequence analysis of the disposal of vitrified high-level waste in the case of the normal evolution scenario - ONDRAF/NIRAS report R-3383. ONDRAF/NIRAS, Brussel (Belgium).

Mallants, D., Marivoet, J., Sillen, X., 2001. Performance assessment of vitrified high-level waste in a clay layer. Journal of Nuclear Materials 298 (1-2), 125-135.

Mertens, J., Vandenberghe, N., Wouters, L., Sintubin, M., 2003. The origin and development of joints in the Boom Clay Formation (Rupelian) in
Belgium. In: Van Rensbergen, P., Hillis, R.R., Maltman, A.J., Morley, C.K. (Eds.), Subsurface Sediment Mobilization. Special Publication, vol. 216. Geological Society, London, pp. 309-321.

Mertens, J., Bastiaens, W., Dehandschutter, B., 2004. Characterization of induced discontinuities in the Boom Clay around the underground excavations (URF, Mol, Belgium). Applied Clay Science 26 (1-4), 413-428.

Mourzenko, V.V., Thovert, T., Adler, P.M., 1995. Permeability of a single fracture: validity of the Reynolds equation. Journal de Physique II (5), 465-482.

Wemaere, I., Marivoet, J., 1995. Geological Disposal of Conditioned High-Level and Long Lived Radioactive Waste: Updated Regional Hydrogeological Model for the Mol site (The North-Eastern Belgium Model) — ONDRAF/NIRAS Report R-3060. ONDRAF/ NIRAS, Brussel (Belgium).

Wemaere, I., Marivoet, J., Labat, S., Beaufays, R., Maes, T., 2002. Mol-1 Borehole (April-May 1997): Core Manipulations and Determination of Hydraulic Conductivities in the Laboratory - ONDRAF/NIRAS Report R-3590. ONDRAF/NIRAS, Brussel (Belgium).

Witherspoon, P.A., Wang, J.S.Y., Iwai, K., Gale, J.E., 1980. Validity of cubic law for fluid-flow in a deformable rock fracture. Water Resources Research 16 (6), 1016-1024.

Therrien, R., Sudicky, E.A., 1996. Three-dimensional analysis of variably-saturated flow and solute transport in discretely-fractured porous media. Journal of Contaminant Hydrology 23 (1-2), 1-44.

Therrien, R., Sudicky, E.A., McLaren, R.G., 2003. FRAC3DVS: an Efficient Simulator for Three-Dimensional, Saturated-Unsaturated Groundwater Flow and Density Dependent, Chain-Decay Solute Transport in Porous, Discretely-Fractured Porous or Dual-Porosity Formations, User's Guide.

Yeo, I.W., de Freitas, M.H., Zimmerman, R.W., 1998. Effect of shear displacement on the aperture and permeability of a rock fracture. International Journal of Rock Mechanics and Mining Sciences 35, $1051-1070$. 